\title{
A NEW FAMILY OF WASPS ${ }^{1}$
}

\author{
By Howard E. Evans \\ Museum of Comparative Zoology
}

The classification of the aculeate Hymenoptera is considerably complicated by the existence of a number of small families of doubtful relationships, families such as the Plumariidae, Rhopalosomatidae, Sierolomorphidae, Sclerogibbidae, and Loboscelidiidae. To add still another family to this list is a dubious distinction, and to base such a family on twelve specimens may be considered a dubious procedure. Nevertheless these twelve specimens present such an unusual array of structural features that they can scarcely be ignored. Although some of these features are clearly specializations, others are so very generalized, for Aculeata, that there can be little question that this family is a relict of a very ancient stock of wasps. These wasps have the habitus of certain Scolioidea, and probably the family should be placed in that superfamily. However, because of the 13 -segmented antennae in the female and the lack of closed cells in the hind wings, the family will fall in the Bethyloidea in most classifications. The name of the type genus, Scolebythus, is meant to imply a sharing of certain characteristics of both these superfamilies of primitive Aculeata (scol being a prefix derived from Scolia, lebythus an anagram of Bethylus). Further discussion of the relationships of the family is deferred until after the descriptive material. In the description of the family, I have numbered the more significant characters so that these can be referred to more readily later on.

\section{Scolebythidae, new family}

Small wasps (known species 7-10 $\mathrm{mm}$. long), fully winged, without strong sculpturing, known from the female sex only. Head vertical, hypognathous (I); head broad below, rather thick, the temples strongly developed. Hypostomal carinae well separated from mouthparts, forming a very broad $\mathrm{V}$, the arms of which reach the ventral condyle of the mandibles (2). Labial palpi short, but with four segments (3). Maxillary palpi with six segments, the segments slightly flattened and bearing some strong setae. Mandibles unusually short and broad, measuring from 1.5 to $2 \times$ as long as broad at the base, the apex with four strong teeth in an oblique series (4). Clypeus

\footnotetext{
${ }^{1}$ Published with the aid of a grant from the Museum of Comparative Zoology.

Manuscript received by the editor June 11, 1962.
} 
exceedingly short, extending beyond the antennal sockets by less than the diameter of the latter; median basal portion of clypeus extending triangularly upward between the antennal sockets, nearly reaching the level of the top of the sockets (5). Face depressed laterad of each antennal socket for reception of the scape. Rims of antennal sockets slightly raised on upper side, the sockets opening obliquely downward, not overhung by ridges (6). Antennae with thirteen segments (7); scape much flattened, slightly curved; flagellum simple, covered with short, suberect setulae. Malar space well developed, at least a third as long as width of mandibles at their base. Ocellar triangle at or slightly below level of tops of eyes, vertex rounded off well above ocelli and eye tops; occipital carina present or absent. Pronotum short, with a short dorsal surface and a strong, nearly vertical anterior face, but the collar virtually absent, revealing an open, membranous space between the tops of the propleura (8); posterior lateral lobes of pronotum somewhat rounded, touching the tegulae. Proepisterna very large, produced strongly forward so that the head is well separated from the pronotum (9). Proepimera present at base of front coxae, completely set off by sutures from the proepisterna (IO). Prosternum remarkably large (more than half as long along midline as length of front femur), diamond shaped, the entire venter of the prothorax forming a large flat surface with a $\mathrm{Y}$-shaped suture (the suture separating the prosternum from the proepisterna) (II). Front coxae flattened, compressed against the sternum (I2). Mesosternal region large and somewhat flattened; mesosternum simple, not produced backward over middle coxae (13). Middle coxae separated by an elevated median ridge of the metasternal region ( 14 ), these coxae also slightly flattened. Hind coxae contiguous, their sockets not separated by any sclerotized parts. Mesoscutum with both notauli and parapsidal grooves nearly complete; scutellum at the base with a pair of widely separated, transverse pits. Metanotum a narrow transverse band, sometimes concealed medially by the scutellum. Propodeum with a basal transverse area which is longer on the midline than the metanotum and which is set off from the remainder of the propodeum by a strong suture (15); propodeal disc with the slope low and even, without sculpturing or a strong posterior rim. Mesopleura large and convex, without sculpturing except for a vertical suture passing downward from the posterior lobes of the pronotum, marking off a small epicnemium (16). All femora moderately broadened and compressed; legs completely without spines but bearing some unusually long setae ( 17 ). Tibial spurs I-2-2. Claws slender, simple except subdentate basally ( I 8 ). Fore wing with a stigma and a closed marginal cell, also with one submarginal cell and 
one fully closed discoidal cell, the second (lower) discoidal cell being closed below and on the outer side by obsolescent veins (19); outer part of wing membrane devoid of veins and cells (except marginal cell), but having three strong, parallel, unbranched hyaline streaks (20). Hind wing without closed cells, with only two short veins at the base (2I) ; anal lobe distinct, large, fully .3 as long as total length of hind wing (22). Abdomen large, its articulation with the propodeum rather broad; first tergite broad at base, its anterior face strongly concave, fitting against the propodeum (23). No constriction whatever between first and second abdominal segments; first sternite arcuately prolonged backward, overlying the second sternite (24). Apex of abdomen directed upward slightly, distinctly flattened dorsoventrally, the apical sternite in particular rather flat (25). Sting and sting-sheaths strongly developed. (Figs. I-8).

\section{Key to Genera}

Occipital carina well developed; malar space short, less than half as long as width of mandibles at their base; apex of marginal cell on the wing margin; abdomen robust, the fifth sternite simple (Fig. 3) (Madagascar)

Scolebythus new genus

Occipital carina absent; malar space well over half as long as width of mandibles at their base; apex of marginal cell curving away from wing margin; abdomen slender, the fifth sternite slightly swollen posteriorly, the swelling terminating behind in a polished, triangular area which is flanked by two groups of dense, appressed setae (Fig. 7) (Brazil)

Clystopsenella Kieffer

\section{Scolebythus new genus}

Type and only known species: $S$. madecassus n. sp.

Scolebythus madecassus new species

Plate 2, figs. I-4

Type: 9 , MADAGASCAR: Mandritsara (Wulsin coll.) (Mus. Comp. Zool., no. 30494).

Description. - Length $7 \mathrm{~mm}$.; fore wing $6.3 \mathrm{~mm}$. Body piceous, shining; legs and antennae wholly dark brown. Wings hyaline, with a faint yellowish tinge, fore wing with a weak apical fuscous band; costa, subcosta, and stigma dark brown, remaining veins amber to yellowish. Entire body covered rather sparsely with golden-brown setae, mostly rather short, but distinctly longer toward the tip of the 
abdomen and also on the tibiae. Head very slightly wider than high (Fig. I). Clypeus with a broad but very short median lobe, the margin of which is slightly concave, paralleled by a series of setae. Front slightly alutaceous, with many very small punctures, barely impressed medially. Minimum distance between eyes I.I $5 \times$ height of an eye; inner orbits closest near the middle, weakly divergent above, strongly divergent below. Posterior ocelli situated on an imaginary line drawn between eye tops; width of ocellar triangle (including ocelli) I.I $5 \times$ ocello-ocular line; distance from posterior ocelli to occipital carina $1.5 \times$ width of ocellar triangle. Basal enclosure of propodeum much longer than metanotum, its posterior margin obtusely angulate; enclosure as well as main part of propodeum with a median groove, especially strong behind. Front femora $2.7 \times$ as long as wide; hind femora longer and somewhat more compressed, but of about the same proportions. Wings as shown in Fig. 2.

Remarks. - This species is known only from the type.

\section{Genus Clystopsenella Kieffer}

Clystopsenella Kieffer, 1911, Ann. Soc. Sci. Bruxelles, $35: 204$.

Kieffer, 1914, Das Tierreich, 41 : 555-556.

Type species: C. longiventris Kieffer, monobasic.

Kieffer included Clystopsenella in the subfamily Bethylinae of the Bethylidae, and in fact the wings do bear much resemblance to those of certain genera of that subfamily, especially Eupsenella. However, in virtually every respect Clystopsenella departs radically in structure from the Bethylinae, in fact from all Bethylidae, as discussed further below.

\section{Clystopsenella longiventris Kieffer \\ Plate 2, figs. 5-8}

Clystopsenella longiventris Kieffer, 1911, op. cit., p. 204 ( 9, BRAZIL: St. Paul and Villanova; type and paratype in British Museum).

Description. - Length $7 \mathrm{~mm}$.; fore wing $4 \mathrm{~mm}$. Head testaceous, the vertex with three brownish streaks, one starting at the ocellar triangle and one at the upper end of each eye, all extending backward but not extending over the top of the vertex; mandibles testaceous, the teeth dark; first two antennal segments light brown, rest of antenna dark brown. Thorax wholly testaceous to pale castaneous, slightly darker on anterior face of pronotum, sides of mesoscutum, metanotum, pleura, and venter; legs wholly testaceous; abdomen pale castaneous, each segment with an indistinct paler apical band. Wings hyaline, weakly tinged with brownish along the veins, the veins and 
stigma brown. Head slightly wider than high. Clypeus with no evidence of a median lobe, but each side with a pair of rounded lobes which extend over the dorsal mandibular condyles (Fig. 5). Front shining, with a linear median impression which does not quite reach the anterior ocellus; punctures of front small, virtually absent above the ocellar triangle. Minimum distance between eyes I.I $\times$ height of an eye; inner orbits closest at the middle, weakly diverging above and below. Posterior ocelli situated well below an imaginary line drawn between eye tops; width of ocellar triangle $\mathrm{I} . \mathrm{I} \times$ ocello-ocular line; distance from posterior ocelli to top of vertex more than $1.5 \times$ width of ocellar triangle. Basal enclosure of propodeum very short except medially, where it is roundly produced backward (Fig. 6); basal enclosure and propodeal disc barely impressed medially. Front femora about twice as long as wide; hind femora much flattened, measuring about $2.2 \times$ as long as wide. Fore wing as figured by Kieffer, 1914, Fig. 195; marginal, submarginal, and first discoidal cell somewhat shorter than in Scolebythus madecassus, and the tip of the marginal cell turned away from the wing margin.

Remarks. - This description is drawn from the paratype, which is virtually identical to the type but in somewhat better condition. I have recently seen nine additional females of this species: eight from the Rio Caraguata, Matto Grosso, Brazil, collected by Fritz Plaumann in March, I953; and one from Nova Teutonia, Santa Catarina, Brazil, taken by the same collector in December 1962 (collections of the Univ. of Kansas and Mus. Comp. Zool.). These specimens vary in size from 7 to $10 \mathrm{~mm}$. (not counting the sting, which extends up to $3 \mathrm{~mm}$. beyond the abdomen), the fore wing from 4 to $6 \mathrm{~mm}$. In this series the body color varies from deep fusco-castaneous to piceous; it is nearly uniformly colored except that the abdomen tends to be slightly paler basally and apically and the less deeply colored specimens show evidence of markings on the vertex similar to those described above; the mandibles and legs are bright testaceous throughout the series. In these darker specimens the golden-brown body setae stand out strongly, particularly the long, rather dense setae on the apical tergite. Despite the darker color, I cannot believe that these specimens represent a different species, as structurally they are nearly identical to the types of longiventris (which were collected long ago and may have faded). One notes that in all nine specimens the basal enclosure of the propodeum tends to be subangulate behind rather than rounded as figured; and in three specimens the ocellar triangle is more compact than usual, the ocello-ocular line being subequal to or slightly greater than the width of the ocellar triangle. 
Psyche, 1963
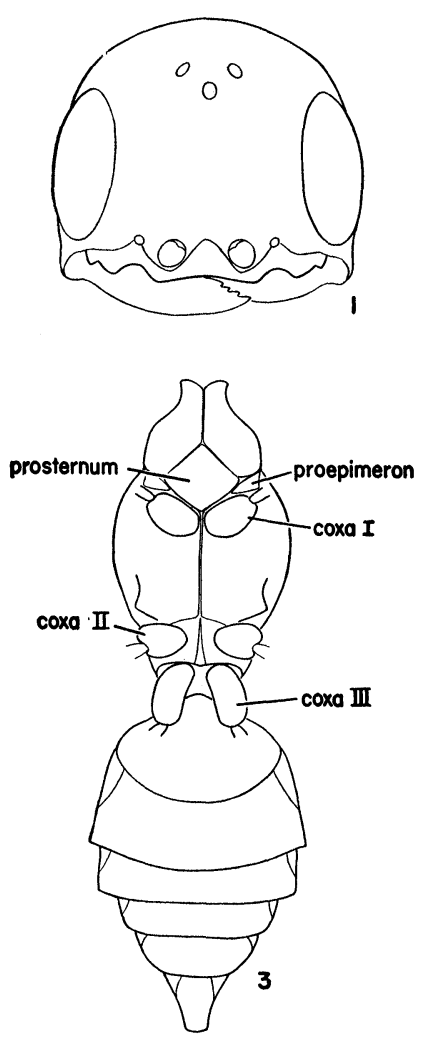

Vol. 70, Plate 2
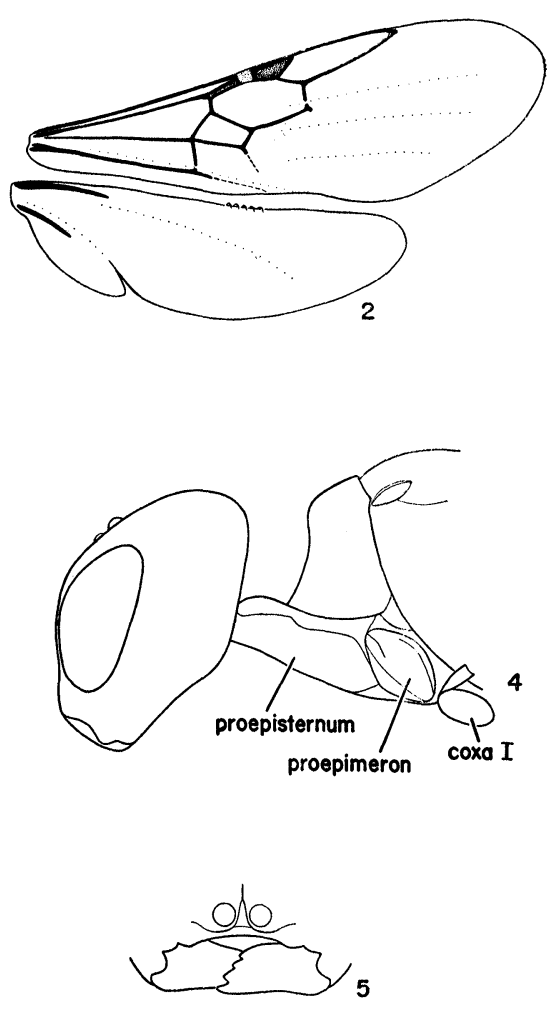

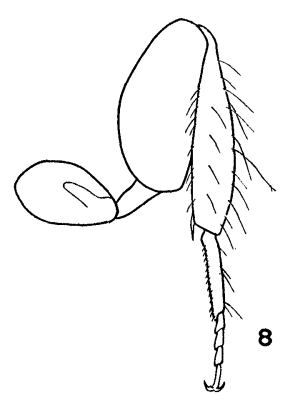

Evans - SCOLEBYTHIDAE 


\section{POSITION OF THE SCOLEBYTHIDAE}

Characters relating them to the Scolioidea. - The superficial habitus of these wasps suggests that of certain of the Tiphiidae, some elements of which are presumed to be close to the ancestral stock of the Aculeata. Particular characters suggesting the tiphiids (more particularly the Anthoboscinae) are the broad, vertical head, the foursegmented labial palpi, the simple antennal orbits, the absence of a pronotal collar, the slightly separated middle coxae and contiguous hind coxae, the broadened and compressed femora and hairy legs, the closed marginal cell and tendency for unbranched streaks on the outer part of the wing membrane, and the broad first tergite. A simple mesosternum is found in the Scolioidea in the family Sapygidae, and the concave first tergite and general conformation of the abdomen also suggest the Sapygidae.

Characters relating them to the Bethylidae. - Antennae with thirteen segments in the female sex are the rule in the Bethylidae, but the antennae are normally I2-segmented in female Scolioidae. The simple mesosternum, slightly separated middle coxae, and contiguous hind coxae are characters which may be taken to relate these wasps to the Bethylidae as well as to certain Scolioidae. The most striking bethylid feature is the hind wing, which is very similar to that of most Bethylidae. The venation of the fore wings is unusual for a bethylid, but in itself would not rule out a relationship to Eupsenella and other Bethylinae. Most Bethylidae which have a relatively full venation have a series of complex, branching streaks on the outer part of the membrane.

In general, the resemblances to the Bethylidae are not impressive. The Aculeata were undoubtedly derived from ancestors with multiarticulate antennae, and it is possible that primitive Scolioidea went through a stage in which both sexes had I3-segmented antennae. These are small wasps, and one would expect reductions in wing venation. Many of the smaller scolioids exhibit various reductions in venation, but in no case are the wings as bethylid-like as in the Scolebythidae.

Explanation of Plate 2

Figs. 1-4, Scolebythus madecassus n. sp. Fig. 1, anterior view of head, antennae omitted. Fig. 2, wings. Fig. 3, ventral view of thorax and abdomen, legs beyond coxae and sting and sting-sheaths omitted. Fig. 4, lateral view of head and prothorax.

Figs. 5-8, Clystopsenella longiventris Kieffer. Fig. 5, clypeus, mandibles, and antennal sockets. Fig. 6, dorsal view of thorax and base of abdomen. Fig. 7, ventral view of abdomen. Fig. 8, lateral view of hind leg.

Figures are drawn to various scales. 
Unique and apparently primitive characters. - The prosternum of these wasps is of unusual interest. A large, flat, triangular or diamondshaped prosternum occurs in a few sawflies (e.g. Syntexis) and a few parasitoids (e.g. Spilochalcis), but virtually all Aculeata have the prosternum much reduced and somewhat sunken, or even practically absent. The Sapygidae have a somewhat larger and less sunken prosternum than most Aculeata, but even here the resemblance to the Scolebythidae is not great. The free proepimeron is also most unusual. I find no evidence of this structure in most Aculeata examined, but in the Plumariidae the proepimeron is fairly well developed, although not quite so completely set off as in the Scolebythidae. The large first sternite of the abdomen, which extends arcuately backward and broadly overlaps the second sternite, is also unusual, as in most primitive Aculeata the first sternite is short and there is at least some evidence of the beginnings of a constriction at this point: this is true in such groups as the Anthoboscinae, the Sapygidae, and the Bethylidae. However, in the Plumariidae the condition is almost exactly the same as in the Scolebythidae.

Unique and apparently specialized characters. - Here I would include the broad mouth opening and powerful mandibles, the reduced clypeus, and the strong malar space; on the thorax the elongate proepisterna, perhaps the large prosternum, and the flattened coxae. These characters together surely make up a single adaptive complex, and give the anterior part of these insects a striking resemblance to that of certain parasitoids which attack wood borers (most particularly the Aulacidae). I feel there can be little question that the Scolebythidae attack wood-boring larvae, probably of beetles (since most Scolioidae and many Bethylidae attack beetle larvae). Probably they enter the burrows of the beetles to find their hosts. After I had come to these conclusions I sent specimens to Dr. J. G. Betrem for examination, and he expressed exactly the same opinion.

Summary of characteristics. - Of the 25 characters numbered in my diagnosis of the family on an earlier page, the following are primitive aculeate characters not necessarily relating these wasps to any other aculeate group: 3, I3, I4, I7, I8, 22. The following characters appear especially primitive and unlike other Aculeata: IO, I I, I 5, 24 (but the Plumariidae possess 15 and 24 , and 10 in some measure). The following are bethylid characters: 7, 19, 21 (but see discussion above). The following specializations make up an adaptive complex appearing to fit these wasps as parasites of wood-boring beetle larvac: 2, 4, 8, 9, I2, perhaps also I I. The remaining characters are shared 
with certain of the primitive Scolioidae such as the Anthoboscinae and Sapygidae: I, 5, 6, I6, 20, 23, 25. Because of the preponderance of scolioid and primitive aculeate characters, I feel that this family unquestionably belongs in the Scolioidea. However, in artificial keys stressing wing venation and antennal segmentation, it may be desirable to key the family out with the Bethylidae.

Are the scolebythids female plumariids? Within the Scolioidea, the Scolebythidae appear to represent an isolated group; no less than io of the 25 characters considered are discussed above as in some measure "unique and apparently primitive" or "unique and apparently specialized". Yet several of these unusual features are shared, at least to some extent, with the Plumariidae. Since the Plumariidae are known from males only, and from South America and South Africa only, it is necessary to ask if the scolebythids may be female plumariids. I concede this possibility, but I think it unlikely for the following reasons. (I) The plumariids have closed cells in the hind wing, and the venation of the fore wing bears little resemblance to that of the scolebythids. (2) The prosternum of the plumariids is small and sunken. (3) The middle coxae of the plumariids are subcontiguous, and the legs very much longer than in the scolebythids. (4) There is little resemblance in the general configuration of the head and thorax, except in the several characters cited in the preceding paragraph. (5) Plumarius occurs chiefly in arid regions of Chile, Argentina, and Peru, and is surely not common, if it occurs at all, in Brazil. I am not aware that Myrmecopterina, the South African and only other known genus, has been found in Madagascar.

It may be argued that in several groups of Tiphiidae (most particularly the Methochinae and Brachycistidinae) the sexual dimorphism is nearly as great. It is greater, in fact, with respect to the wings, which are absent in the females of these tiphiids; in the scolebythids the wings of the female may merely have undergone much reduction in venation without much loss of size. 'The various apparent specializations of these wasps for attacking wood-borers might, of course, have evolved in the female sex only, just as only the female Brachycistidinae have become modified for living underground. However, at this stage of our knowledge it seems to me wiser to consider the scolebythids a distinct family than to place Clystopsenella in the synonymy of Plumarius and to consider the Madagascar specimen a female Myrmecopterina, an assignment that may prove to be very wide of the mark. The erection of a new family may serve as a challenge to workers to seek more data on these insects. 


\section{ACKNOWLEDGEMENTS}

I have showed specimens of these wasps to several eminent hymenopterists and solicited comments from them. All of their suggestions have been considered carefully, and several have been incorporated into the above discussion. All agreed that these wasps are not bethylids, and the majority agreed that the erection of a new family was justified. These men were J. G. Betrem, J. C. Bradley, C. Jacot-Guillarmod, K. V. Krombein, C. F. W. Muesebeck, and O. W. Richards. I wish to express my thanks to all of these men.

Examination of the types of Clystopsenella longiventris Kieffer at the British Museum was made possible by a grant from the Permanent Science Fund of the American Academy of Arts and Sciences. 

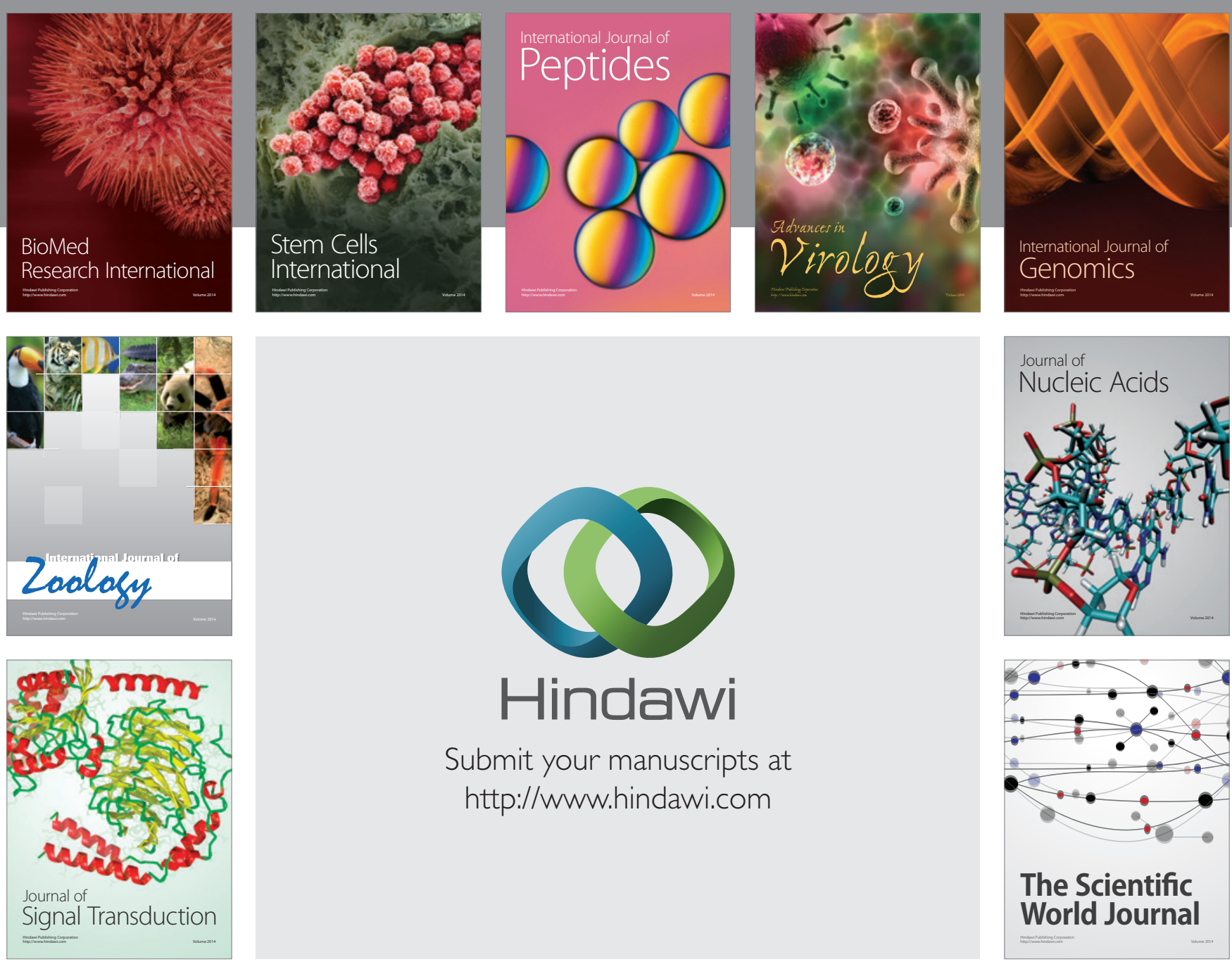

Submit your manuscripts at

http://www.hindawi.com
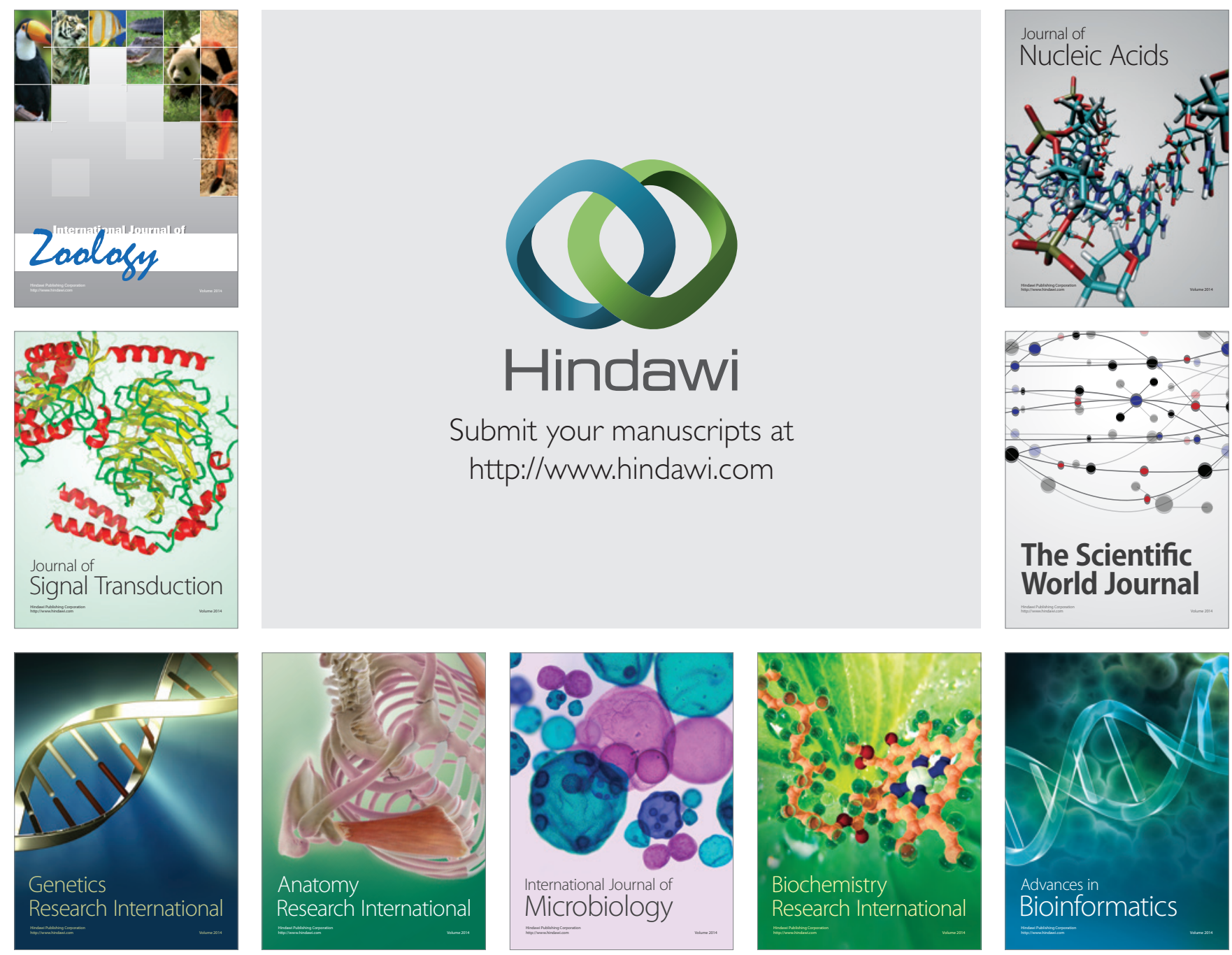

The Scientific World Journal
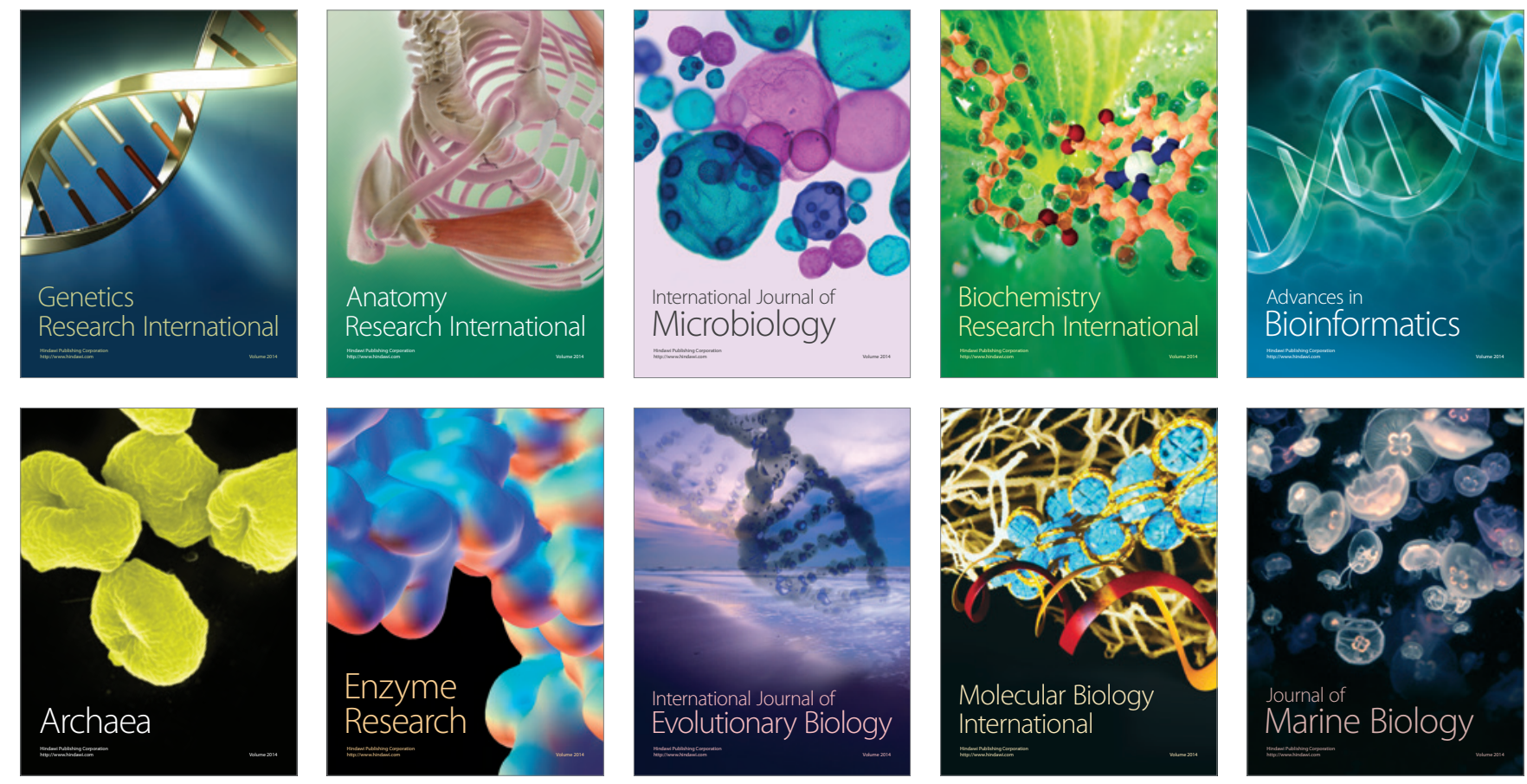